\title{
Compression of the right coronary artery by an aortic pseudoaneurysm after infective endocarditis: an unusual case of myocardial ischemia
}

This article was published in the following Dove Press journal:

Clinical Interventions in Aging

\author{
Juan Lacalzada-Almeida' \\ Alejandro De la Rosa- \\ Hernández' \\ María Manuela Izquierdo- \\ Gómez' \\ Javier García-Niebla ${ }^{2}$ \\ Iván Hernández-Betancor ${ }^{1}$ \\ Juan Alfonso Bonilla- \\ Arjona $^{3}$ \\ Antonio Barragán-Acea' \\ Ignacio Laynez-Cerdeña' \\ 'Cardiology Department, Hospital \\ Universitario de Canarias, Tenerife, \\ ${ }^{2} \mathrm{Health}$ services from the Health \\ Area of El Hierro, Valle del Golfo \\ Health Center, El Hierro, ${ }^{3}$ Radiology \\ Department, Hospital Universitario \\ de Canarias, Tenerife, Spain
}

Correspondence: Juan Lacalzada-Almeida Cardiac Imaging Laboratory, Department of Cardiology, Hospital Universitario de Canarias, Ofra s/n, La Cuesta, 38320 La Laguna, Tenerife, Spain Tel +34922678450

$\mathrm{Fax}+34922677190$

Email jlacalzada@gmail.com

\begin{abstract}
A 61-year-old male with a prosthetic St Jude aortic valve size 24 presented with heart failure symptoms and minimal-effort angina. Eleven months earlier, the patient had undergone cardiac surgery because of an aortic root dilatation and bicuspid aortic valve with severe regurgitation secondary to infectious endocarditis by Coxiela burnetii and coronary artery disease in the left circumflex coronary artery. Then, a prosthesis valve and a saphenous bypass graft to the left circumflex coronary artery were placed. The patient was admitted to the Cardiology Department of Hospital Universitario de Canarias, Tenerife, Spain and a transthoracic echocardiography was performed that showed severe paraprosthetic aortic regurgitation and an aortic pseudoaneurysm. The 64-slice multidetector computed tomography confirmed the pseudoaneurysm, originating from the right sinus of Valsalva, with a compression of the native right coronary artery and a normal saphenous bypass graft. On the basis of these findings, we performed surgical treatment with a favorable postoperative evolution. In our case, results from complementary cardiac imaging techniques were crucial for patient management. The multidetector computed tomography allowed for a confident diagnosis of an unusual mechanism of coronary ischemia.
\end{abstract}

Keywords: pseudoaneurysm, infective endocarditis, myocardial ischemia, aortic valve prosthesis

\section{Photo essays}

A 61-year-old male patient was admitted to our hospital with heart failure because of a bicuspid aortic valve with severe regurgitation, secondary to Q-fever infective endocarditis (IE). Prior to cardiac surgery, invasive coronary angiography was performed, which showed a severe proximal lesion in the left circumflex coronary artery (LCX). A prosthetic St Jude aortic valve size 24 and a saphenous bypass graft to LCX were placed, with no postoperative complications. Eleven months later, the patient was readmitted with heart failure and minimal-effort angina. A transthoracic echocardiography (TTE) was performed, and an image of an aortic pseudoaneurysm was detected in TTE (Figure 1A, C and D). A severe paraprosthetic aortic regurgitation was observed (Figure 1B), following which a 64-slice multidetector computed tomography (MDCT) was performed. The presence of an aortic pseudoaneurysm originating from the right sinus of Valsalva was successfully shown in the volume rendering images (Figure 2). In the MDCT axial views, the pseudoaneurysm was localized in the anterior wall of the thoracic aorta, showing contrast enhancement within it (Figure 3A and C), as well as an ascending aortic aneurysm, up to the aortic arch (Figure 3B). The MDCT revealed compression of the native right coronary artery (RCA) due to the pseudoaneurysm (Figure 3D), this being the cause for the probable ischemia in this area. The LCX had 

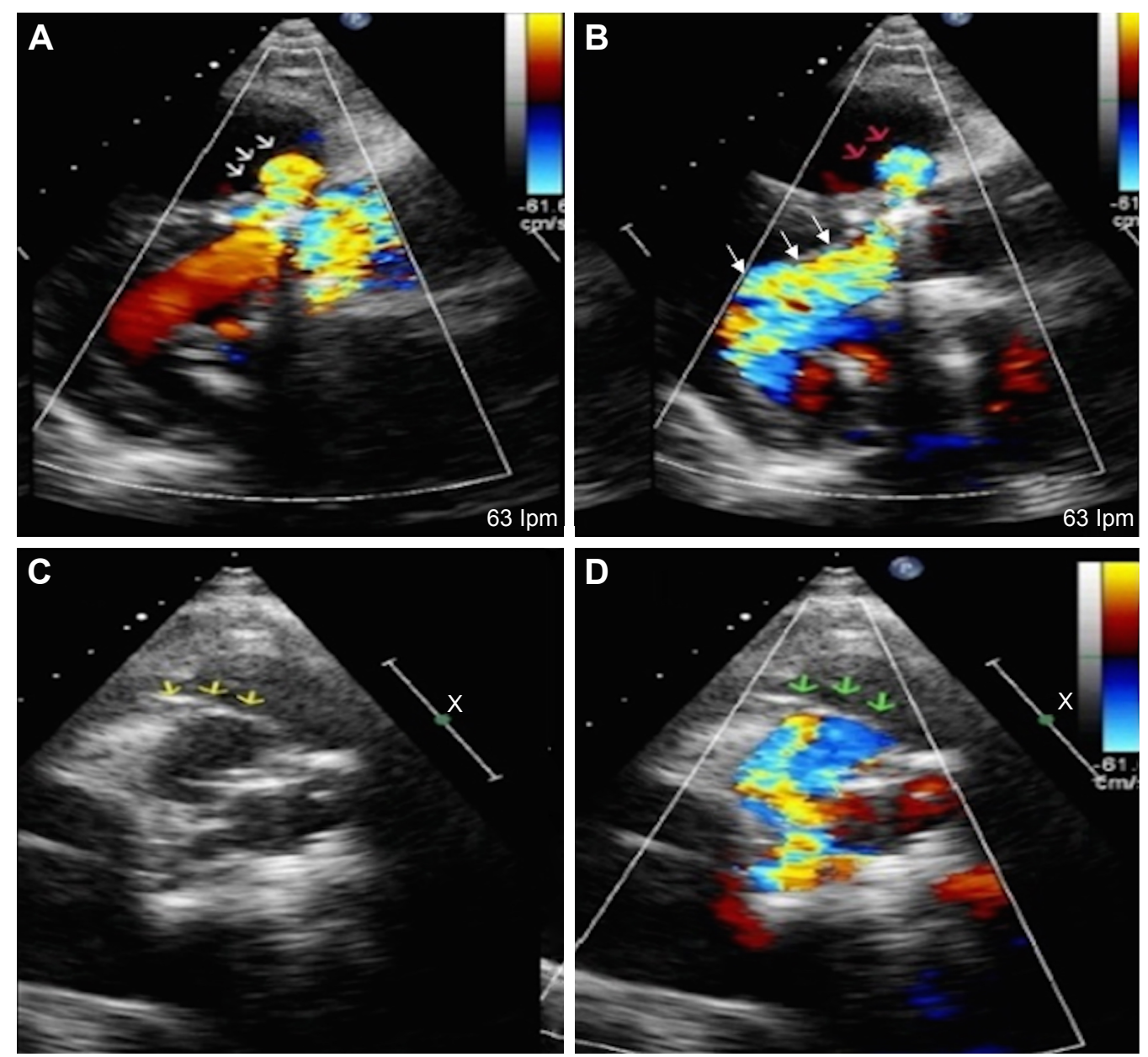

Figure I Echocardiography study.

Notes: (A) Paraesternal long-axis view in systole with pseudoaneurysm at supra-annular level next to the right coronary sinus (white arrows) and (B) diastole with pseudoaneurysm (red arrows) and severe paraprosthetic aortic regurgitation (white arrows). (C) Paraesternal short axis view in diastole with pseudoaneurysm and RCA (yellow arrows) and (D) systole with pseudoaneurysm and RCA (green arrows).

Abbreviation: RCA, right coronary artery.

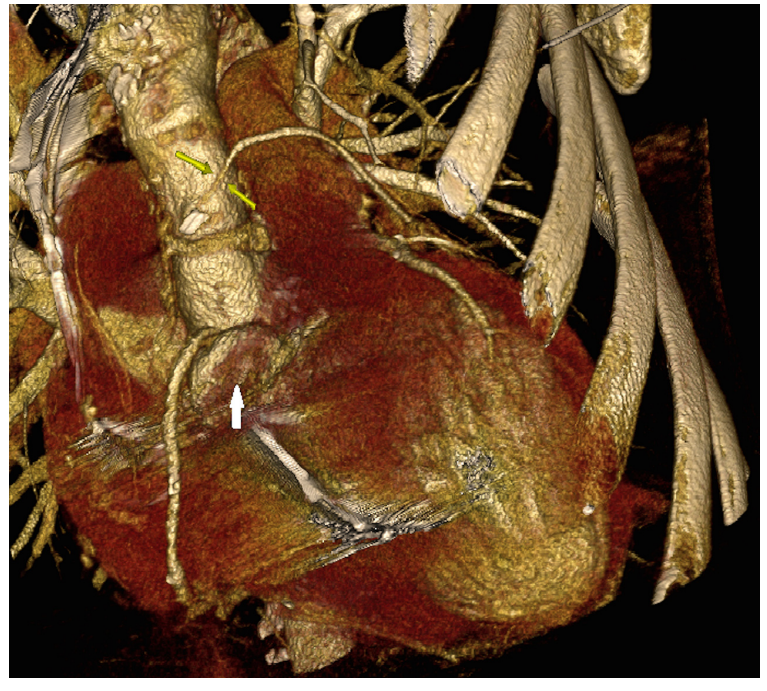

Figure 2 MDCT volume rendering image shows compression of the RCA by the aortic pseudoaneurysm (white arrow) and the saphenous venous bypass graft (yellow arrow).

Abbreviations: MDCT, multidetector computed tomography; RCA, right coronary artery. a chronic occlusion and the venous grafting was functioning properly (Figure 3E). MDCT oblique reconstruction also showed the aortic prosthesis valve (Figure 3F). The Bentall-De Bono procedure was performed, with resection of the pathological section of the root and ascending aorta and replacement using composite valve-graft prosthesis, using a bioprosthetic valve. The coronary ostiums and the venous grafting to LCX were reimplanted.

Pseudoaneurysm may be located in the mitral-aortic intervalvular fibrosa due to perivalvular complications of $\mathrm{IE}^{1}$ or secondary to aortic valve surgery complications. ${ }^{2}$ It can also be located in relation with the aortic root. ${ }^{2}$ Other authors described systolic compression by pseudoaneurysm of the left main coronary artery, ${ }^{1}$ of the left anterior descending, ${ }^{3}$ and of the RCA. ${ }^{2}$ In our case, the complementary use of cardiac imaging techniques was crucial for the management of the patient. Even having a prosthetic mechanic aortic valve and coronary bypass surgery, the MDCT allowed a confident 

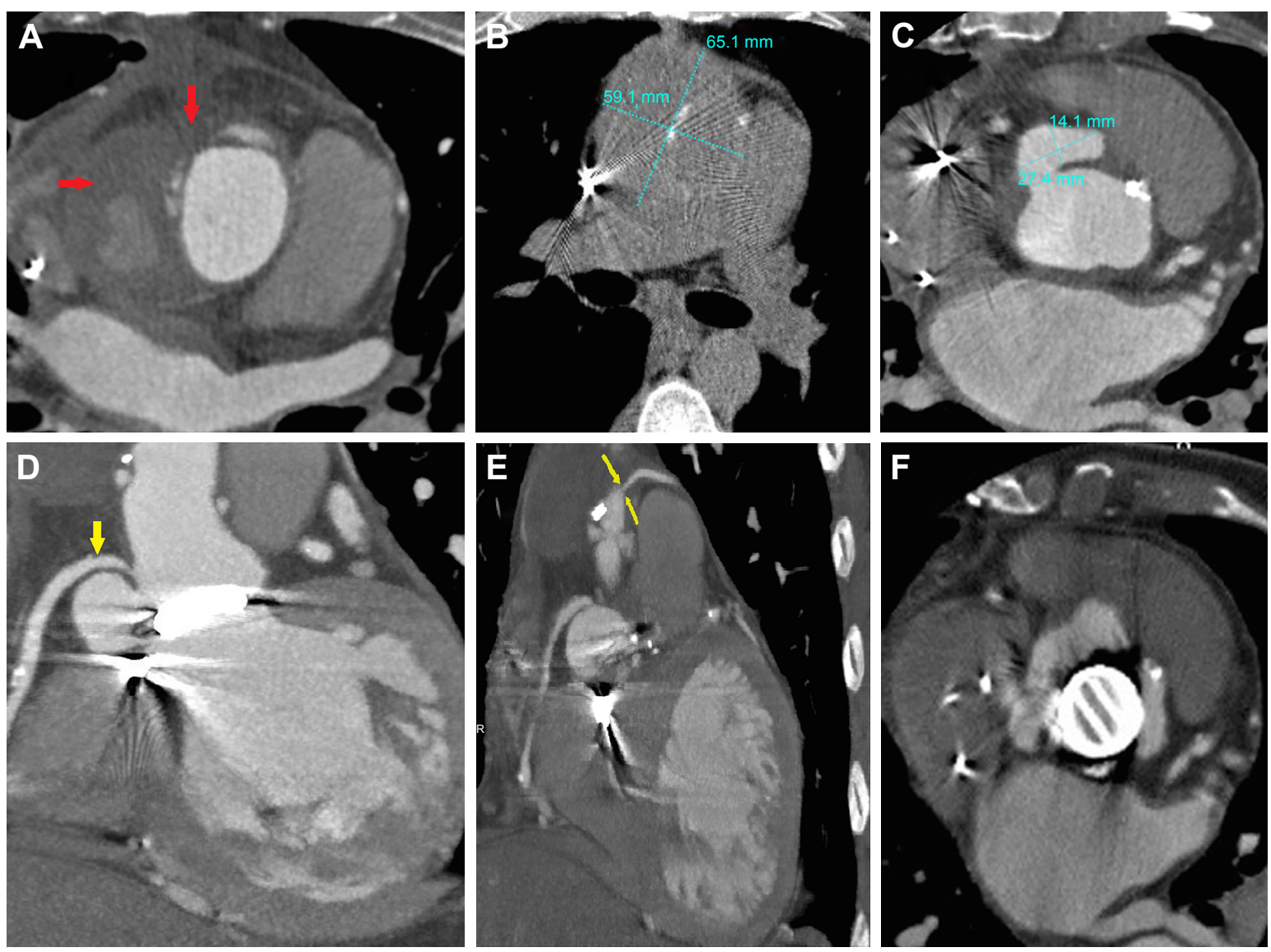

Figure 3 Multidetector computed tomography study.

Notes: (A) The oblique reconstruction of the MDCT shows contrast enhancement and areas of thrombosis within the aortic pseudoaneurysm (red arrows). (B) Axial CT slice showing ascending aortic aneurysm and pseudoaneurysm of $59.1 \times 65.1 \mathrm{~mm}$ up to the arch. (C) MDCT oblique reconstruction of aortic pseudoaneurysm. (D) MDCT oblique reconstruction with RCA and aortic pseudoaneurysm (yellow arrow). (E) Multiplanar reconstruction of saphenous venous bypass graft (yellow arrow). (F) MDCT oblique reconstruction of aortic prosthesis valve.

Abbreviations: MDCT, multidetector computed tomography; RCA, right coronary artery.

diagnosis of an unusual mechanism of probable coronary ischemia, since it showed the compression of the RCA by the pseudoaneurysm, guiding the surgical treatment, after which the patient recovered adequately.

\section{Consent}

The patient provided written informed consent for the case and accompanying images to be published.

\section{Disclosure}

The authors report no conflicts of interest in this work.

\section{References}

1. Parashara DK, Jacobs LE, Kotler MN, et al. Angina caused by systolic compression of the left coronary artery as a result of pseudoaneurysm of the mitral-aortic intervalvular fibrosa. Am Heart J. 1995; 129(2):417-421.

2. Zientara A, Häussler A, Genoni M, Dzemali O. 41 Years after BjörkShiley valve implantation: advanced preparation of a giant root pseudoaneurysm entrapping the right coronary artery. Eur J Cardiothorac Surg. 2015;48(3):512-513.

3. Bouabdallaoui N, Achouh P, Lacaze-gadonneix J, Ennezat PV. Unusual cause of acute coronary syndrome: dynamic coronary compression by an aortic pseudoaneurysm. Eur Heart J Cardiovasc Imaging. 2014; 15(4):468-469.

Clinical Interventions in Aging

\section{Publish your work in this journal}

Clinical Interventions in Aging is an international, peer-reviewed journal focusing on evidence-based reports on the value or lack thereof of treatments intended to prevent or delay the onset of maladaptive correlates of aging in human beings. This journal is indexed on PubMed Central, MedLine,

\section{Dovepress}

CAS, Scopus and the Elsevier Bibliographic databases. The manuscript management system is completely online and includes a very quick and fair peer-review system, which is all easy to use. Visit http://www.dovepress. com/testimonials.php to read real quotes from published authors. 